\title{
Mutation-in-Brief
}

\section{A Novel Mutation of the Glucokinase Gene in Maturity- onset Diabetes of the Young Type 2 (MODY2)}

\author{
Wakako $\mathrm{Jo}^{1}$, Kenji Fujieda ${ }^{2}$, and Toshihiro Tajima ${ }^{1}$ \\ ${ }^{I}$ Department of Pediatrics, Hokkaido University School of Medicine, Hokkaido, Japan \\ ${ }^{2}$ Department of Pediatrics, Asahikawa Medical College, Hokkaido, Japan
}

Maturity-onset diabetes of the young (MODY) is a genetically and clinically heterozygous type of diabetes mellitus characterized by early onset (often before $25 \mathrm{yr}$ of age) and absence of pancreatic autoimmunity markers (1). Mutations in six distinct genes have been implicated in the six different types of diabetes (MODY1-6) $(1,2)$. One of these six genes encodes the glycolytic enzyme glucokinase (GCK) (associated with MODY2), and the other five encode the following transcription factors: hepatocyte nuclear factor (HNF)-4 $\alpha$ (MODY1), HNF-1 $\alpha$ (MODY3), insulin promoter factor 1 (IPF-1; MODY4), HNF-1 $\beta$ (MODY5) $(1,2)$ and BETA2/NEUROD1 (MODY6).

MODY2 caused by mutation of the GCK gene is mild with stable hyperglycemia. These patients are usually treated with diet alone and rarely develop diabetes-associated complications $(3,4)$. Here, we describe a novel mutation in the GCK gene in a family with MODY2.

The patient was a full-term infant. Her height was $47 \mathrm{~cm}$, and her birth weight was 3,236 g; she was delivered after an uncomplicated pregnancy. Neonatal screening for congenital hypothyroidism found an elevated level of thyroid-stimulating hormone (TSH; $213 \mu \mathrm{U} / \mathrm{ml}$ ),

Received: August 31, 2009

Accepted: December 21, 2009

Correspondence: Dr. Wakako Jo, Department of Pediatrics, Hokkaido University School of Medicine,

N15, W7, Sapporo, Hokkaido 060-0835, Japan

E-mail: wakakojo@med.hokudai.ac.jp and so she was referred to our hospital at $18 \mathrm{~d}$ of age for L-T4 treatment. At 5 yr of age, thyroid scintigraphy showed an ectopic thyroid gland. At 16 yr of age, she was screened for blood glucose and $\mathrm{HbA}_{1 \mathrm{c}}$ on the basis of her mother's fasting hyperglycemia during two pregnancies, as well as in her two maternal uncles and grandfather. At this time, her height was $158.5 \mathrm{~cm}$, and her weight was $43.6 \mathrm{~kg}$ (BMI $\left.17.4 \mathrm{~kg} / \mathrm{m}^{2}\right)$. Biochemical evaluation showed that her fasting plasma glucose level was $152 \mathrm{mg} / \mathrm{dl}$; her $\mathrm{HbA}_{1 \mathrm{c}}$ level was $6.0 \%$, and there was an absence of pancreatic autoimmunity markers. An oral glucose tolerance test showed moderate elevation of plasma glucose (176 mg/dl) at $120 \mathrm{~min}$ after glucose challenge. Her insulinogenic index was 1.2 (normal range: $1.34 \pm 0.66)$, and her HOMA-IR and HOMA- $\beta$ indices were 1.61 and 55.3, respectively (normal ranges for HOMA-IR and HOMA- $\beta$ : $\leq 1.6$ and 40-60, respectively). Glimepiride treatment was initiated, but her compliance with the medication regimen was poor, and treatment was stopped at $19 \mathrm{yr}$ of age. Without medication, her $\mathrm{HbA}_{1 \mathrm{c}}$ level remains $5.4 \%$.

Based on her family history and mild diabetes mellitus, she was suspected to have MODY2. The GCK gene was amplified from genomic DNA and sequenced directly. The institutional review board approved this study, and informed consent for DNA analysis was obtained from her and her parents.

A heterozygous transition mutation (GGG to GAG) was identified at codon 193 (G193E) 


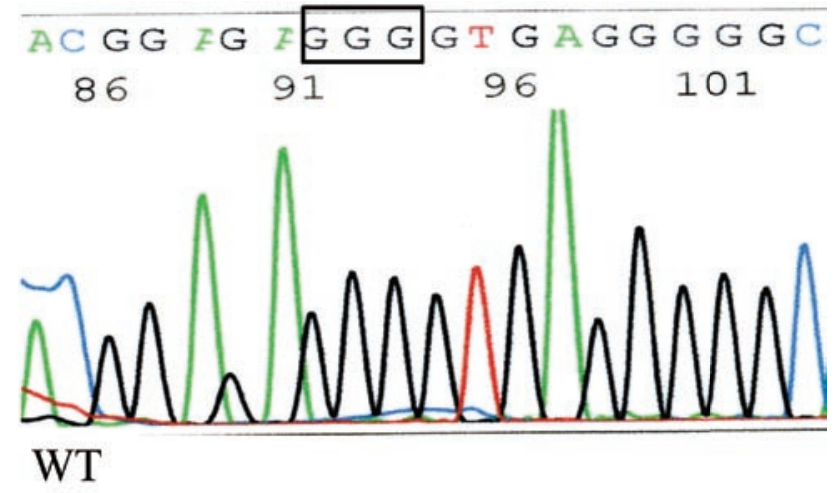

ACG G FG $A G G G T$ G A G G G GC 85 GGG(Gly) $\rightarrow$ GAG (Glu)

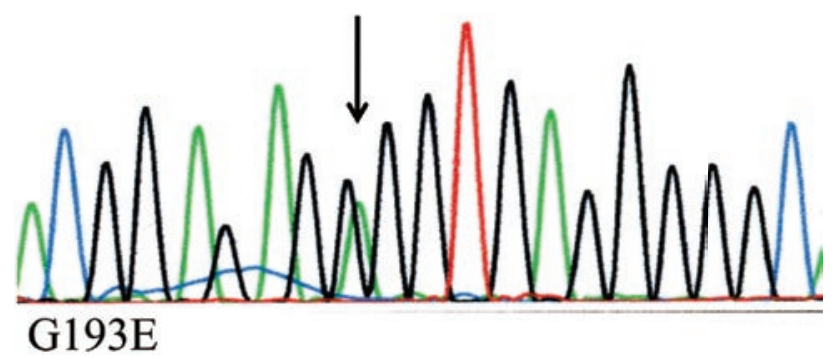

Fig. 1 Sequence of the GCK gene. The patient had a heterozygous mutation. An arrow indicates the mutation site.

(Fig. 1). Her mother had an identical mutation. Analysis of both alleles at the GCK locus from 100 healthy control individuals failed to detect the mutation, and it was not found in either the Japanese SNP (JSNP) or dbSNP databases.

While we did not determine the functional consequence of the mutant GCK allele, several lines of evidence suggest that it might represent a novel disease-causing mutation. Specifically another missense mutation at the same codon (G193R) was previously found in an Italian patient with MODY2 (4). Furthermore, glycine 193 is highly conserved among species. Finally, the glucose binding site in GCK is formed in part by residues 204-206 (5), suggesting the possible involvement of glycine 193 in glucose binding based on its proximity to these residues. Future studies will shed more light on this possibility.

It has been reported that more than $85 \%$ of patients with GCK mutations are managed on diet alone, and some individuals diagnosed in childhood have been able to stop drug treatment [1]. Therefore, early diagnosis of MODY2 based on this and other GCK mutations would allow for discontinuation of unnecessary medication and may also be useful in the future for genetic counseling.

\section{References}

1. Owen K, Hattersley AT. Maturity-onset diabetes of the young: from clinical description to molecular genetic characterization. Best Pract Res Clin Endocrinol Metab 2001;15:309-23.

2. Winter WE. Molecular and biochemical analysis of the MODY syndromes. Pediatr Diabetes 2000;1:88-117.

3. Fajans SS, Bell GI, Polonsky KS. Molecular mechanisms and clinical pathophysiology of maturity-onset diabetes of the young. N Engl J Med 2001;345:971-80.

4. Massa O, Meschi F, Cuesta-Munoz A, Caumo A, Cerutti F, Toni S, et al. High prevalence of glucokinase mutations in Italian children with MODY. Influence on glucose tolerance, firstphase insulin response, insulin sensitivity and BMI. Diabetologia 2001;44:898-905.

5. Mahalingam B, Cuesta-Munoz A, Davis EA, Matschinsky FM, Harrison RW, Weber IT. Structural model of human glucokinase in complex with glucose and ATP. Impications for the mutants that cause hypo- and hyperglycemia. Diabetes 1999;48:1698-705. 